\title{
Analysis of the pSK1 replicon, a prototype from the staphylococcal multiresistance plasmid family
}

\author{
Correspondence \\ Neville Firth \\ nfirth@bio.usyd.edu.au
}

Received 10 February 2008

Revised 20 June 2008

Accepted 27 June 2008

\author{
Stephen M. Kwong, Ricky Lim, Rebecca J. LeBard,† Ronald A. Skurray \\ and Neville Firth
}

School of Biological Sciences, University of Sydney, New South Wales 2006, Australia

\section{INTRODUCTION}

It is common for Staphylococcus aureus isolates to harbour one or more plasmids that range in size from less than $2 \mathrm{~kb}$ up to $60 \mathrm{~kb}$. The small plasmids $(<10 \mathrm{~kb})$ generally replicate by a rolling-circle (RC) mechanism and are cryptic or encode a single resistance determinant (Paulsen et al., 1997; Firth \& Skurray, 2006). The larger staphylococcal plasmids appear to be mosaic structures with a backbone consisting of replication, maintenance and sometimes transfer functions, and insertion sequences, transposons and small RC plasmids are frequently integrated into this backbone; the transposons and RC plasmids typically carry antimicrobial resistance determinants. Hence, many large theta-replicating plasmids confer resistance to more than one antimicrobial compound and are collectively termed multiresistance plasmids. Staphylococcal multiresistance plasmids have been broadly divided into three groups based on resistance phenotypes and conjugative ability; (i) the $\beta$-lactamase/heavy-metalresistance plasmids, (ii) pSK1-like multiresistance plasmids; and (iii) conjugative pSK41-like multiresistance plasmids (Paulsen et al., 1997; Firth et al., 2000). DNA sequence analyses have shown that representative replicons from each of these three staphylococcal multiresistance plasmid groups (pI9789::Tn552, pSK1 and pSK41,

tPresent address: School of Biotechnology and Biomolecular Sciences, University of New South Wales, NSW 2052, Australia.

Abbreviations: CAT, chloramphenicol acetyltransferase; EMSA, electrophoretic mobility shift assay; TSP, transcriptional start point. respectively) are, in fact related, and the plasmids actually utilize evolutionarily common replication systems (Firth et al., 2000). pSK1 and examples of the $\beta$-lactamase/heavymetal-resistance plasmids belong to the same incompatibility group, whereas pSK41 has been shown to be compatible with these plasmids (Firth et al., 2000).

In recent years, the number of staphylococcal plasmids known to represent pSK1- and pSK41-related replicons has grown, largely due to the complete genome sequencing of clinical staphylococcal strains. The genome sequences of two hospital strains of multidrug-resistant S. aureus, N315 (an MRSA strain isolated in 1982) and Mu50 (a low-level vancomycin-resistant MRSA strain isolated in 1997), revealed that both strains harboured a multiresistance plasmid (pN315 and pVRSA, respectively) belonging to the pSK1 replicon type (Kuroda et al., 2001). Plasmids bearing pSK1-like replicons have also been identified in Staphylococcus saprophyticus type strain ATCC 15305, frequently associated with urinary tract infections (plasmids pSSP1 and pSSP2; Kuroda et al., 2005), biofilmproducing Staphylococcus epidermidis RP62a (pSERP; Gill et al., 2005), non-pathogenic S. epidermidis strain ATCC 12228 (plasmids pSE-12228-04 and pSE-12228-05; Zhang et al., 2003), the bacteriocin producer Staphylococcus warneri ISK-1 (pPI-1; Aso et al., 2005), multidrug-resistant Staphylococcus haemolyticus (pNVH97A; Anthonisen et al., 2002) and Staphylococcus xylosus (pSX267; Gering et al., 1996), fusidic-acid-resistant S. aureus (pUB101; O'Brien et al., 2002), and streptogramin-resistant S. aureus (pIP680; Allignet \& El Solh, 1999). Similarly, genetic analysis of an $S$. 
aureus strain displaying high-level resistance to vancomycin showed the presence of pLW1043, a pSK41-like conjugative plasmid, that had acquired the vanA resistance transposon, Tn1546 (Weigel et al., 2003). Another pSK41like replicon which encodes resistance to mupirocin and macrolide, lincosamide and streptogramin B compounds, pUSA03, was found in strain USA300, which is a cause of serious community-acquired MRSA infections that are becoming increasingly prevalent in North America and Europe (Diep et al., 2006).

We have previously characterized the pSK41 replication region, showing that the Rep protein directly binds iterons found centrally within the rep coding region and that Rep expression, and hence pSK41 copy number, is negatively regulated by an antisense RNA, RNAI (Kwong et al., 2004, 2006). Although there is considerable sequence similarity between the pSK1 and pSK41 rep coding regions, the similarity fades upstream of the rep genes, where pSK41 RNAI is transcribed. This, and the fact that pSK41 and pSK1 are compatible, suggests that there are significant differences between their replication systems. Here we describe a molecular analysis of the pSK1 replicon, facilitating comparisons between the pSK41 and pSK1 replication systems that respectively serve as prototypes for the conjugative and non-conjugative multiresistance plasmids of staphylococci.

\section{METHODS}

Bacterial strains and growth conditions. Escherichia coli $\mathrm{DH} 5 \alpha$ was used as the host strain for all cloning procedures and E. coli BL21 was used for expression of polyHis-tagged Rep protein. All other procedures were performed using S. aureus RN4220 as the host. The relevant properties of these bacterial strains are listed in Table 1. Bacterial cultures were grown at $37^{\circ} \mathrm{C}$ in Luria-Bertani (LB) medium (Sambrook et al., 1989) with aeration, or on plates composed of LB medium containing $1.5 \%(\mathrm{w} / \mathrm{v})$ Oxoid agar, except for $S$. aureus electroporation procedures, where a combination of B2 medium and NYE medium was used to culture cells as described previously (Schenk \& Laddaga, 1992). When required, antibiotics were added to media at the following final concentrations: ampicillin (Ap), $100 \mu \mathrm{g} \mathrm{ml} l^{-1}$;

Table 1. Bacterial strains and plasmids used in this study

Abbreviations: Ap, ampicillin; Cm, chloramphenicol; Em, erythromycin; Gm, gentamicin; Km, kanamyin; Qac, quaternary ammonium compounds; Tb, tobramycin; Tc, tetracycline; Tp, trimethoprim; MCS, multiple cloning site. Refer to Fig. 1 for plasmids containing various pSK1 rep region fragments cloned into pSK6799 to delimit the minimal replicon.

\begin{tabular}{|c|c|c|}
\hline Strain or plasmid & Relevant characteristics & Reference or source \\
\hline \multicolumn{3}{|l|}{ Escherichia coli } \\
\hline BL21 & $\mathrm{F}^{-} o m p T h s d S B\left(\mathrm{r}_{\mathrm{B}}^{-} \mathrm{m}_{\mathrm{B}}^{-}\right) d c m$ gal & Novagen \\
\hline \multicolumn{3}{|c|}{ Staphylococcus aureus } \\
\hline RN4220 & Restrictionless derivative of NCTC $8325-4$ & Kreiswirth et al. (1983) \\
\hline pBR322 & $\mathrm{Ap}^{\mathrm{R}} \mathrm{Tc}^{\mathrm{R}}$ & Sambrook et al. (1989) \\
\hline pSK1 & $\mathrm{Tp}^{\mathrm{R}} \mathrm{Qac}^{\mathrm{R}} \mathrm{Gm}^{\mathrm{R}} \mathrm{Tb}^{\mathrm{R}} \mathrm{Km}^{\mathrm{R}}$, S. aureus multiresistance plasmid & Simpson et al. (2003) \\
\hline pSK639 & $\mathrm{Tp}^{\mathrm{R}}$, S. epidermidis resistance plasmid & Apisiridej et al. (1997) \\
\hline pSK4833 & $\begin{array}{l}\mathrm{Ap}^{\mathrm{R}} \mathrm{Em}^{\mathrm{R}}, 1.4 \mathrm{~kb} \text { pSK1 replicon cloned into BamHI and HindIII sites } \\
\text { of plasmid pWE180 }\end{array}$ & Firth et al. (2000) \\
\hline pSK5487 & $\mathrm{Ap}^{\mathrm{R}} \mathrm{Cm}^{\mathrm{R}}$, pSK41-based shuttle vector & Kwong et al. (2004) \\
\hline pSK6799 & $\begin{array}{l}\mathrm{Ap}^{\mathrm{R}} \mathrm{Cm}^{\mathrm{R}} \text {, pGEM5Zf with cat gene from pSK5299 cloned into the } \\
\text { SacI and SalI sites }\end{array}$ & This study \\
\hline pSK6829 & $\begin{array}{l}\mathrm{Ap}^{\mathrm{R}} \mathrm{Tc}^{\mathrm{R}} \mathrm{Tp}^{\mathrm{R}}, \mathrm{pBR} 322 \text { with the } \mathrm{pSK} 639 \text { replication region and } d f r A \text { gene } \\
\text { from pSK1 (BglII fragment) cloned into the AatII site }\end{array}$ & This study \\
\hline pSK6847 & $\mathrm{Ap}^{\mathrm{R}} \mathrm{Tp}^{\mathrm{R}}$, pSK6829 with pSK1 rnaI cloned into the BamHI site & This study \\
\hline pSK6848 & $\mathrm{Ap}^{\mathrm{R}} \mathrm{Tp}^{\mathrm{R}}$, pSK6829 with pSK1 oriV cloned into the BamHI site & This study \\
\hline pSK6854 & $\mathrm{Ap}^{\mathrm{R}} \mathrm{Cm}^{\mathrm{R}}$, pSK5481 with premature stop codon replacing codon 10 of rep & This study \\
\hline pSK6860 & $\mathrm{Ap}^{\mathrm{R}} \mathrm{Em}^{\mathrm{R}}, \mathrm{pSK} 4833$ containing the $\mathrm{A} 1204 \mathrm{C}_{\mathrm{P}}$ rnaI mutation & This study \\
\hline pSK6890 & $\mathrm{Ap}^{\mathrm{R}} \mathrm{Cm}^{\mathrm{R}}$, pSK5481 containing the $\mathrm{A} 1204 \mathrm{C} \mathrm{P}_{\text {rnal }}$ mutation & This study \\
\hline
\end{tabular}


erythromycin (Em), $20 \mu \mathrm{g} \mathrm{ml}^{-1}$; trimethoprim (Tp), $50 \mu \mathrm{g} \mathrm{ml}{ }^{-1}$; chloramphenicol $(\mathrm{Cm}), 10 \mu \mathrm{g} \mathrm{ml}^{-1}$ in S. aureus and $7 \mu \mathrm{g} \mathrm{ml}^{-1}$ in E. coli.

DNA manipulations. Plasmid DNA was isolated and purified from $E$. coli using the alkaline lysis procedure (Birnboim \& Doly, 1979) or the Quantum Prep plasmid miniprep kit (Bio-Rad). The same method was used to isolate plasmid DNA from $S$. aureus except that the cells were first lysed by adding $0.2 \mathrm{mg}$ lysostaphin $\mathrm{ml}^{-1}$ (Sigma) to the cell resuspension and incubating them at $37{ }^{\circ} \mathrm{C}$ for $30 \mathrm{~min}$. Cloning in $E$. coli was accomplished using standard methods (Sambrook et al., 1989); restriction enzymes and T4 DNA ligase were purchased from New England Biolabs. Cloned fragments were checked by DNA sequencing. Plasmids were routinely introduced into S. aureus RN4220 cells by electroporation (Schenk \& Laddaga, 1992) of approximately $0.5 \mu \mathrm{g}$ DNA. PCR and in vitro mutagenesis were carried out using PfuTurbo DNA polymerase (Stratagene) and automated DNA sequencing was performed by the Australian Genome Research Facility. Quantity One software (Bio-Rad) was used for quantitative image analysis of electrophoretically fractionated DNA.

The RNAI promoter mutation described in this study was a singlebase substitution and converted the -10 hexamer from $5^{\prime}$-TATAAT$3^{\prime}$ to $5^{\prime}$-TATAAG-3' using the complementary primer pair SK1-R16 (5'-TTT GAT ACT TGT CTT ATA TAT ATC TAC) and SK1-R17 (5'-GTA GAT ATA TAT AAG ACA AGT ATC AAA). Disruption of the pSK1 rep ORF was accomplished by replacing the G residue at the first position of codon 10 with the TA dinucleotide using the primers SK1-R18 (5'-ATA TCT GCA AGT TAA ATT CGA AAC ATT ACG) and SK1-R19 (5'-CGT AAT GTT TCG AAT TTA ACT TGC AGA TAT), which simultaneously introduced a premature stop codon and destroyed the EcoRI restriction site.

An E. coli-S. aureus shuttle vector was constructed by PCR amplification of the replication region from pSK639 (nucleotides 2987-4482; GenBank entry U40259; Apisiridej et al., 1997) using primers SK639-01 (5'-CCG ACG TCA GAT CTG GTA TAG TTG CGA ACT-3') and SK639-02 (5'-CCG ACG TCG ACA GTT TTT GGG TTT ATT AAG-3') and ligation of the amplicon into the AatII site of pBR322. The resulting plasmid was then used to clone the $d f r A$ gene from plasmid pSK1, contained within a $2.7 \mathrm{~kb} B g l \mathrm{II}$ fragment, into the unique BglII site, resulting in pSK6829. The pSK1 rnaI gene was PCR amplified using the primers pSK1-R10 (5' -CCG GAT CCT TTA TAT ACA CCT TTA A-3') and pSK1-R32 (5'-CCG GAT CCT CAT TTC CTT TTA CTT AG-3') and cloned into the BamHI site of pSK6829, resulting in plasmid pSK6847. Similarly, the pSK1 oriV region was PCR amplified using the primers pSK1-R33 (5'-CCG GAT CCT TAT AAA CGA AAG ACA AGG-3') and pSK1-R34 (5'-CCG GAT CCG AAT TCT TAG AAA TCA TG-3') and cloned into pSK6829, resulting in plasmid pSK6848.

Chloramphenicol acetyltransferase (CAT) assays. CAT assays based on the method of Shaw (1975) were adapted to a microplate format as described previously (Kwong et al., 2004). Lysostaphin, acetyl coenzyme A and 5,5'-dithiobis(2-nitrobenzoic acid) were purchased from Sigma Aldrich and BSA from New England Biolabs. CAT units are expressed as nanomoles of chloramphenicol acetylated per mg protein per min at $37{ }^{\circ} \mathrm{C}$ and are the mean of at least three independent assays.

Plasmid segregational stability assays. Plasmid incompatibility was investigated using segregational stability assays, performed essentially as described by Martin et al. (1987). Trimethoprim selection was maintained during overnight growth and single colonies were tested for the retention of pSK4833 by patching onto medium containing erythromycin.

Primer extension. Total RNA was extracted using Trizol reagent (Gibco-BRL) from exponential-phase cultures of S. aureus RN4220 containing the appropriate plasmid. Glass beads (100 $\mu \mathrm{m}$; Sigma) in combination with a bead beater (Bio 101) were used for cell lysis. Primer extension was performed essentially as described by Ausubel et al. (1987) using M-MuLV reverse transcriptase (New England Biolabs). Sequencing ladders were prepared with the SequiTherm EXCEL II DNA sequencing kit (Epicentre Technologies) and pSK4833 as template DNA. Primer PEX12 (5'-CGA ACG CAA ATC GTT TTA ATT ACC-3') was used to identify the pSK1 rep mRNA start point.

Northern blotting. Total RNA was isolated as described above and transferred to a nylon membrane as described previously (Kwong et al., 2006). The pSK1 RNAI-specific riboprobe (corresponding to nucleotides 1108-1310; GenBank entry AF203376) was synthesized in vitro (MEGAshortscript kit; Ambion) using a PCR template generated with the primers pSK1-R30 (5'-GAA ATT AAT ACG ACT CAC TAT AGG ATG AAT TTT AAA AAG CCA ATG-3') and pSK1-R31 (5'CAT AAT AAA AAA CCT CAT TTC C-3'). The riboprobe was treated with calf intestinal phosphatase (New England Biolabs) and subsequently end-labelled by treating with $\mathrm{T} 4$ polynucleotide kinase (New England Biolabs) in the presence of $\left[\gamma_{-}^{32} \mathrm{P}\right]$ ATP (Perkin Elmer). Decade markers (Ambion) were prepared according to the manufacturers instructions.

Protein expression and purification. The pSK1 rep coding region was PCR-amplified using the primer pair SK1-R03 (5'-GGG GTA CCT AAA TTT AAA AAA AAA ATA TC-3', KpnI) and SK1-R02 (5'AAC TGC AGG TTG ATT AAA GAT ATT GTA TTG-3', PstI) and cloned into the respective sites of a pTTQ18 (Stark, 1987) derivative producing a C-terminal $6 \times$ histidine fusion. The integrity of the resulting plasmid was verified by DNA sequencing before being transformed into BL21. Protein expression was induced by adding IPTG ( $1 \mathrm{mM}$ final concentration) to the medium and continuing growth for an additional $3 \mathrm{~h}$. Cells were pelleted and resuspended in native buffer ( $20 \mathrm{mM}$ Tris/ $\mathrm{HCl}, 0.5 \mathrm{M} \mathrm{NaCl}, \mathrm{pH}$ 7.8) then lysed using a micro-sonicator while being chilled on ice. The Rep fusion protein was purified with Probond Ni-NTA resin (Invitrogen) and a 0 $350 \mathrm{mM}$ imidazole gradient in wash buffer $(20 \mathrm{mM}$ Tris/ $\mathrm{HCl}, 0.5 \mathrm{M}$ $\mathrm{NaCl}, \mathrm{pH} 6.0$ ) at $4{ }^{\circ} \mathrm{C}$. Fractions were visualized by SDS-PAGE (Sambrook et al., 1989) and imidazole and salts were removed by gel filtration using a Sephadex PD10 column (AP Biotech) before final storage at $-70{ }^{\circ} \mathrm{C}$ in $20 \mathrm{mM}$ Tris/ $\mathrm{HCl} \mathrm{pH} \mathrm{7.5,20 \% (v/v)} \mathrm{glycerol.}$

DNA-protein binding experiments. The primers SK1-R04 $\left(5^{\prime}-\right.$ CCC AAG CTT ATA AAC GAA AGA CAA GG-3') and SK1-R05 (5' GGA ATT CTT AGA AAT CAT GTT AG-3') were end-labelled using $\left[\gamma_{-}{ }^{32}\right.$ P]ATP (Perkin-Elmer) and T4 polynucleotide kinase (NEB) and used directly in PCR to generate a $261 \mathrm{bp} \mathrm{DNA} \mathrm{fragment.} \mathrm{The}$ labelled DNA was purified with Microcon PCR centrifugal filters (Millipore), eluted in water and stored at $-20{ }^{\circ} \mathrm{C}$. Electrophoretic mobility shift assays (EMSAs) were performed by incubating endlabelled DNA (2000 c.p.m.) with $2 \mu \mathrm{g}$ poly(dI-dC) and increasing amounts of purified Rep protein in $1 \times$ binding buffer $(10 \mathrm{mM}$ Tris/ $\mathrm{HCl}, \mathrm{pH} 7.5,10 \mathrm{mM} \mathrm{MgCl}, 100 \mathrm{mM} \mathrm{NaCl} 2,0.2 \mathrm{mM} \mathrm{DTT}, 10 \%$ glycerol) and a final reaction volume of $50 \mu \mathrm{l}$. Reactions were incubated at $22{ }^{\circ} \mathrm{C}$ for $20 \mathrm{~min}$. Binding reactions were separated on $4.0 \%$ polyacrylamide gels at $22{ }^{\circ} \mathrm{C}$ using a $0.25 \times$ TBE buffering system.

For DNase I footprinting, only primer SK1-R05 was labelled prior to PCR. The resulting DNA fragment, specifically labelled at one end, was incubated with increasing amounts of purified Rep protein under the same conditions used in EMSAs. The volume of the reaction was brought to $200 \mu \mathrm{l}$ with DNase I assay buffer $(10 \mathrm{mM}$ Tris/HCl pH 8.0, $5 \mathrm{mM} \mathrm{MgCl}, 1 \mathrm{mM} \mathrm{CaCl}, 100 \mathrm{mM} \mathrm{KCl}, 2 \mathrm{mM}$ DTT, $50 \mu \mathrm{g}$ BSA ml ${ }^{-1}, 2 \mu \mathrm{g}$ salmon sperm DNA ml${ }^{-1}$ ). DNase I (Sigma) was added (to a concentration that had been predetermined to nick approx. $50 \%$ of DNA once) and the reaction was mixed and 
incubated at room temperature for $2 \mathrm{~min}$. The reaction was stopped by adding $700 \mu \mathrm{l}$ ice-cold DNase I stop buffer ( $92 \%$ ethanol, $3 \mathrm{M}$ sodium acetate, $10 \mu \mathrm{g}$ salmon sperm $\mathrm{DNA} \mathrm{ml} \mathrm{m}^{-1}$ ). Samples were analysed on denaturing $8 \%$ polyacrylamide sequencing gels. The $\mathrm{G}+\mathrm{A}$ sequencing ladder was generated by a rapid method of Maxam and Gilbert sequencing (Sambrook et al., 1989).

Sequence analysis and RNA folding predictions. DNA sequence contigs were assembled using Sequencher (Gene Codes). Sequences were aligned using CLUSTAL $\mathrm{W}$ (Thompson et al., 1994). RNA secondary structures and their free energy values were predicted using the $\mathrm{m}$-fold server (http://frontend.bioinfo.rpi.edu/applications/ mfold; Zuker, 2003).

\section{RESULTS}

\section{Regulation of pSK1 copy number}

In previous studies of the pSK1 par gene, a promoter, $\mathrm{P}_{\text {par- } 4}$, was identified by primer extension immediately upstream of, and divergently oriented from, the rep gene (Simpson et al., 2003). This was thought to be one of several promoters responsible for transcription of the par gene. However, the subsequent identification of an antisense RNA controlling expression of the pSK41 rep gene (Kwong et al., 2004) led us to suspect that $\mathrm{P}_{\text {par-4 }}$ might actually be responsible for production of an equivalent regulatory transcript in $\mathrm{pSK} 1$, since its location with respect to rep is similar to that of $\mathrm{P}_{\text {rnaI }}$ in pSK41. To investigate this possibility, a mutation (A1204C) was introduced into the -10 sequence of this promoter in the pSK1 minireplicon pSK4833 (Fig. 1; Firth et al., 2000); an equivalent mutation has been shown previously to abolish the activity of $\mathrm{P}_{\text {rnaI }}$ of pSK41 (Kwong et al., 2006). Electrophoretic analysis of plasmid DNA isolated from $S$. aureus RN4220 cells containing pSK4833 or the resulting mutant derivative, pSK6860, suggested that the mutation carried by the latter plasmid significantly increased plasmid copy number. Quantitative image analysis indicated that the copy number of pSK6860 was 5- to 10 -fold higher than that of pSK4833 (data not shown). The effect of this mutation was measured more accurately by introducing the A1204C mutation into pSK5481 (Fig. 1), an equivalent pSK1 minireplicon that carries a constitutively expressed cat gene so that relative copy number determinations could be made using CAT assays. This, and the resulting mutant, pSK6890, were each electroporated into RN4220 and CAT assays were performed on soluble protein extracts. The CAT activity from cells bearing pSK5481 averaged $620 \pm 118 \mathrm{nmol}$ chloramphenicol acetylated $\mathrm{min}^{-1}$ per mg total soluble protein at $37^{\circ} \mathrm{C}$, whereas the average CAT activity from pSK6890 was $5053 \pm 977$ units, corresponding to an approximately eightfold increase in plasmid copy number. These results support the notion that the promoter previously identified as $\mathrm{P}_{\text {par- } 4}$ on pSK1 actually directs transcription of an antisense RNA molecule that negatively regulates plasmid copy number, equivalent to

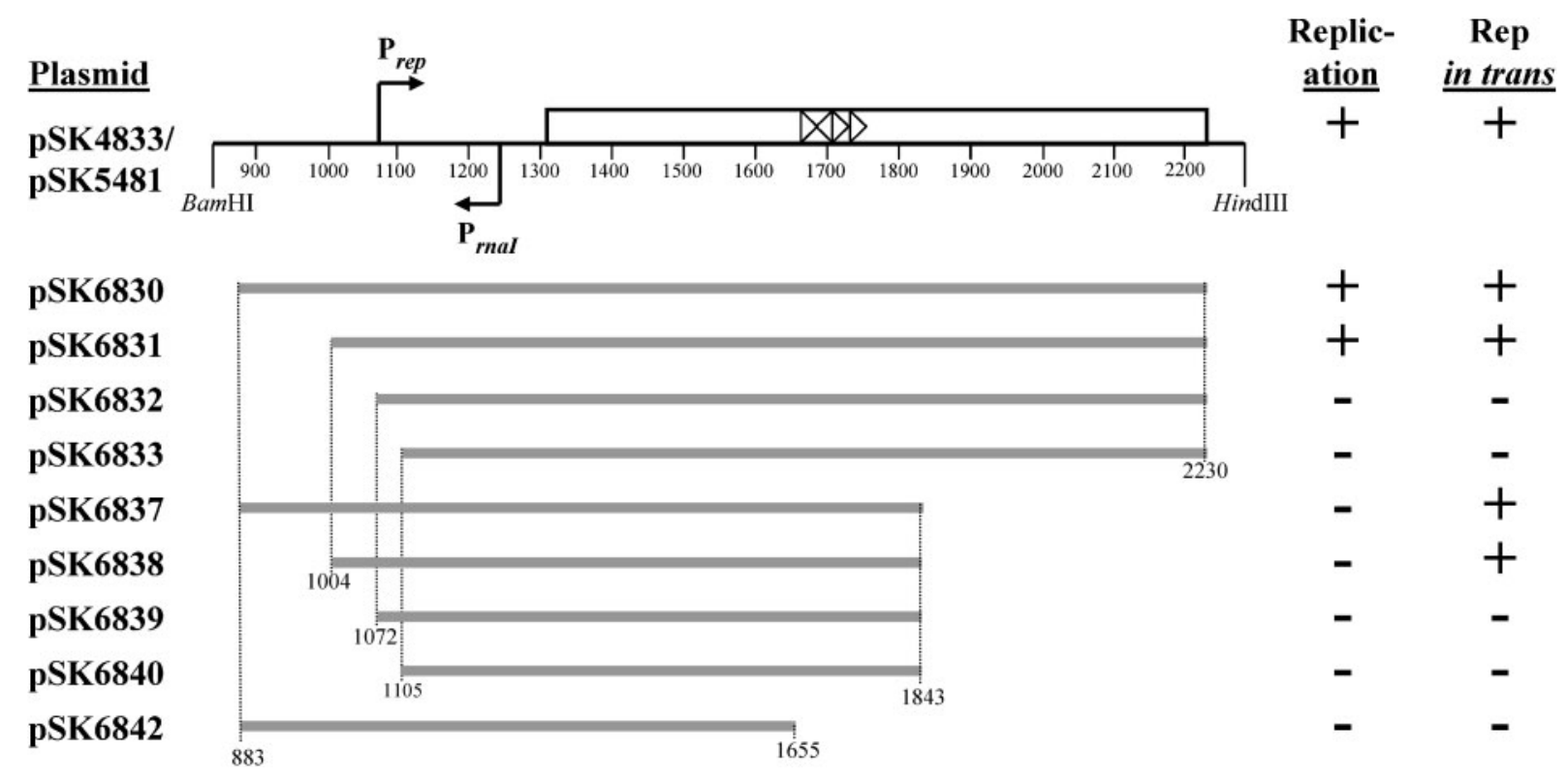

Fig. 1. Genetic and physical map of the pSK1 replication region and deletion derivatives. Plasmid pSK4833 contains the pSK1 replication region from coordinates 842 to 2287 (GenBank entry AF203376). The rep coding region (white box) gives rise to the replication initiation protein and contains four repeat sequences (open arrowheads) in its central region. The positions of the rep and rnal promoters $\left(\mathrm{P}_{\text {rep }}\right.$ and $\left.\mathrm{P}_{\text {rnal }}\right)$ are indicated by arrows. Grey bars indicate the extent and position of fragments carried by deletion plasmids that were generated to localize essential regions. The first column on the right indicates each plasmid's ability (+) or inability (-) to replicate in S. aureus RN4220. The second column indicates each plasmid's replication proficiency in RN4220 when Rep protein is supplied in trans from co-resident plasmid pSK6860. 
pSK41 RNAI; this promoter will therefore be redesignated pSK1 $\mathrm{P}_{\text {rnal }}$.

Direct evidence for the production of pSK1 RNAI was provided by a Northern blotting experiment using total RNA isolated from RN4220 cells harbouring pSK1 or minireplicon derivatives thereof. The resulting blot (Fig. 2) demonstrated the presence of an RNA species of expected size $(\sim 80 \mathrm{nt})$ that hybridized to a riboprobe corresponding to the pSK1 rep mRNA leader in RN4220 cells containing pSK1, pSK4833 or pSK5481, that was absent in cells containing the equivalent $\mathrm{P}_{\mathrm{rnaI}}$ mutant derivatives, pSK6860 or pSK6890.

\section{Re-evaluation of the pSK1 rep transcriptional start point}

Previous primer extension experiments identified a relatively weak transcriptional start point (TSP) $121 \mathrm{nt}$ upstream of the pSK1 rep coding sequence (at nucleotide 1186, GenBank entry AF203376; Simpson et al., 2003). However, this TSP would restrict the overlap between the pSK1 rep message and the RNAI antisense transcript identified above to only $12 \mathrm{nt}$. Furthermore, in subsequent transcriptional analyses of pSK41, we found that a rep primer extension product could only be obtained in the absence of RNAI, presumably because antisense transcripts present in RNA isolations interfere with primer binding to rep mRNA and/or primer extension. We therefore reevaluated pSK1 rep transcription by performing primer extension experiments using RNA isolated from $S$. aureus RN4220 cells harbouring the $\mathrm{P}_{\text {rnaI }}$ mutant minireplicons pSK6860 (Fig. 3) or pSK6890 (data not shown). In both cases, an extension product was obtained that indicated a pSK1 rep TSP located $199 \mathrm{nt}$ upstream of the rep start codon (at nucleotide 1108). A recognizable canonical

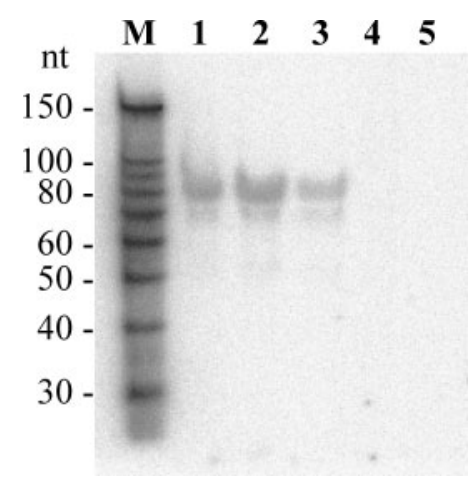

Fig. 2. Detection of pSK1 RNAI by Northern blotting. Total RNA was isolated from S. aureus RN4220 cells harbouring plasmids pSK1 (lane 1), pSK4833 (lane 2), pSK5481 (lane 3), pSK6860 (lane 4) and pSK6890 (lane 5) and co-electrophoresed with size markers (M), on a denaturing $12 \%$ polacrylamide gel. RNA was transferred to a nylon membrane and hybridized with a strandspecific riboprobe for RNAl.

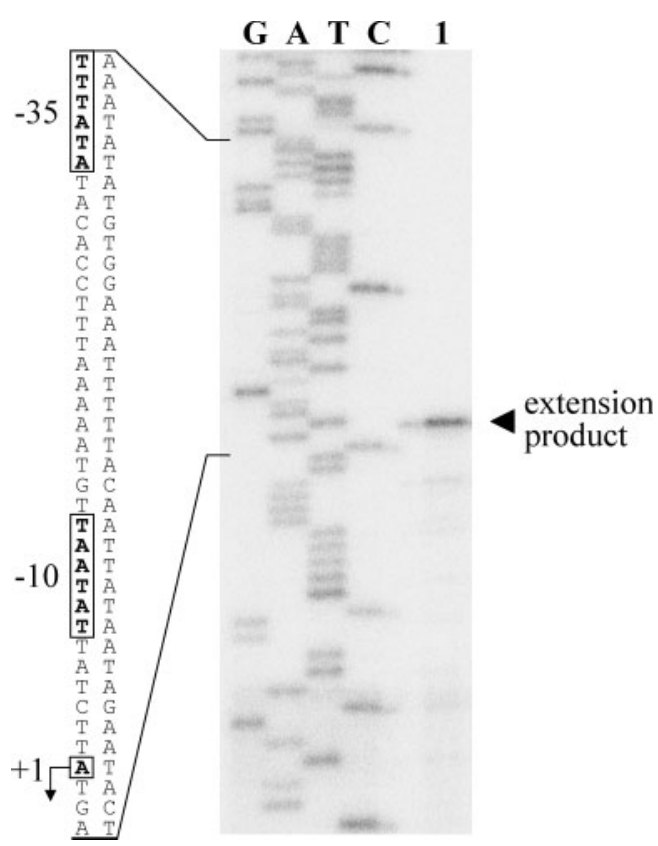

Fig. 3. Identification of the pSK1 rep transcriptional start point. Primer PEX12 was end-labelled and hybridized to total RNA isolated from $S$. aureus RN4220 containing plasmid pSK6860. The double-stranded sequence of the region is shown on the left. Extension of the primer with M-MuLV reverse transcriptase gave an extension product (lane 1), that when compared with a DNA sequencing ladder ( $G, A, T, C)$, corresponded in size to the adenine residue (boxed and marked +1 ) at nucleotide 1108 of pSK1 (GenBank entry AF203376). Canonical promoter sequences $(-10$ and -35$)$ found upstream of the rep TSP are boxed.

promoter with a -35 sequence of TTTATA separated by $17 \mathrm{bp}$ from the -10 sequence TAATAT is appropriately positioned upstream of this TSP (Fig. 3).

\section{Definition of the minimal pSK1 replicon, cis- acting regions, and incompatibility determinants}

To define the minimal region required for pSK1 replication, various PCR fragments encompassing the region were generated by PCR and cloned into the BamHI and $\mathrm{XbaI}$ sites of pSK6799, a derivative of the $E$. coli vector pGEM5Zf ${ }^{+}$that carries a chloramphenicol-resistance gene for selection in $S$. aureus, but which cannot normally replicate in this host. The resulting plasmids (Fig. 1) were then tested for replication proficiency by electroporating them into S. aureus RN4220. Plasmids that gave rise to $\mathrm{Cm}^{\mathrm{r}}$ transformants were deemed to be replication proficient, whereas clones that did not give rise to any transformants were considered replication defective. The smallest of these plasmids that was replication proficient, pSK6831 ( 300 transformants per $\mu \mathrm{g}$ plasmid DNA), contained nucleotides 1004 to 2230 of the pSK1 rep region (Fig. 1; GenBank entry AF203376) and the next-smallest plasmid that could 
not replicate, pSK6832 (no transformants), contained the fragment from nucleotides 1072 to 2230. Together, the replication ability of these two plasmids indicated that the $68 \mathrm{bp}$ region between nucleotides 1004 and 1072 contains sequences essential for replication. The pSK1 rep stop codon is positioned at nucleotide 2225; hence none of the sequences downstream of the rep coding region are required for autonomous replication.

We also sought to perform the replication assays in a system where the Rep protein could be supplied in trans in order to rescue plasmids that had lost the ability to express Rep but that had retained a functional origin of replication. To establish this system, a $2 \mathrm{bp}$ insertion was introduced into the rep gene of pSK5481, creating a premature stop codon and severely truncating the wild-type 306 aa Rep protein to a non-functional 10 aa polypeptide. The resulting plasmid, pSK6854, was confirmed to be replication defective since no transformants could be obtained when it was electroporated into S. aureus RN4220. Electrocompetent RN4220 cells that already harboured pSK4833 $\left(\mathrm{Em}^{\mathrm{R}}\right)$, were expected to be able to supply Rep in trans to rescue pSK6854 but electroporation of these cells with pSK6854 did not result in any transformants that were both $\mathrm{Cm}^{\mathrm{R}}$ and $\mathrm{Em}^{\mathrm{R}}$. Furthermore, we were similarly unable to obtain S. aureus RN4220 cells containing both pSK5481 and pSK4833 (two wild-type pSK1 minireplicons), but could efficiently introduce a compatible pSK41 minireplicon, pSK5487, suggesting that we were observing potent plasmid incompatibility between the pSK1 minireplicons. The strength of this incompatibility was unexpected, because normally two incompatible plasmids can be introduced and maintained within the same cell under selection for both, with plasmid loss occurring after selection is removed. In an attempt to circumvent the incompatibility phenomenon, the electroporation experiments were repeated using $S$. aureus RN4220 cells containing the $\mathrm{P}_{\text {rnaI }}$ mutant pSK6860 described above, since antisense regulators often mediate incompatibility. Transformants were now readily obtained with pSK6854 DNA ( 100 transformants per $\mu \mathrm{g}$ plasmid DNA), consistent with RNAI acting as an incompatibility determinant and confirming that Rep supplied in trans from pSK6860 could rescue a rep mutant pSK1 minireplicon. Similarly, pSK6837 and pSK6838, which lack 384 bp of the $3^{\prime}$-end of the rep coding region (to nucleotide 1843; Fig. 1) could replicate in this strain (producing $\sim 100$ transformants per $\mu \mathrm{g}$ plasmid DNA each). However, pSK6842, which lacks an additional 188 bp (to nucleotide 1656; Fig. 1) that includes the iterated region within rep, could not be rescued (no transformants). Similarly, sequences within the $68 \mathrm{bp}$ region upstream of rep that were found to be required for autonomous replication (described above) were also essential in cis, as indicated by the ability of pSK6860 to rescue pSK6838 but not pSK6839.

To investigate the incompatibility phenomenon observed in more detail, we separately cloned the pSK1 rnaI gene (nucleotides 1072-1307, GenBank entry AF203376) and ori $V$ region (nucleotides 1592-1846) into a compatible $E$. coli-S. aureus shuttle vector, pSK6829, which is derived from the unrelated staphylococcal plasmid pSK639 (Apisiridej et al., 1997). These plasmids were then electroporated into S. aureus RN4220 cells harbouring either the pSK1 minireplicon pSK4833 or the equivalent $\mathrm{P}_{\text {rnaI }}$ mutant plasmid pSK6860. Transformants were obtained harbouring the oriV-containing plasmid (pSK6848), or the vector pSK6829, coresident with pSK4833 or pSK6860; cells harbouring the rnaI-containing plasmid (pSK6847) coresident with pSK6860 were similarly obtained ( 100 transformants per $\mu$ g plasmid DNA in each case). In contrast, we were unable to recover any transformants containing pSK6847 coresident with pSK4833, mirroring the observations for pSK5481 and confirming RNAI as a potent incompatibility determinant. Presumably when RNAI is expressed from both pSK6847 and pSK4833, Rep expression is repressed to such an extent that pSK4833 cannot replicate, so no transformant colonies can grow in the presence of selection for both plasmids. ori $V$-mediated incompatibility was evaluated by determining the effects of pSK6848 and pSK6829 on the segregational stability of coresident pSK4833. After overnight growth in the presence of selection for only pSK6848 and pSK6829 (trimethoprim), $97 \pm 2 \%$ of pSK6829-containing colonies retained pSK4833, as indicated by growth in the presence of erythromycin, whereas only $46 \pm 7 \%$ of pSK6848-containing colonies retained pSK4833, indicating that oriV also acts as a determinant of incompatibility.

\section{pSK1 Rep DNA binding}

The functional requirement for the iterated sequences located within the pSK1 rep coding region in cis as described above was consistent with these being the binding site for the Rep protein, as has been seen for related replication systems (Francia et al., 2004; Kwong et al., 2004; Tanaka et al., 2005). To facilitate confirmation of this, the pSK1 rep coding region was amplified by PCR and cloned into the high-copynumber expression plasmid pTTQ18 (Stark, 1987), so as to encode a C-terminal polyhistidine fusion protein. The recombinant pSK1 Rep protein (hereafter referred to as Rep) was overexpressed in E. coli BL21 and purified by NiNTA affinity chromatography.

The iterated region of pSK1 was amplified by PCR to generate an 250 bp DNA fragment spanning nucleotides 1594 to 1846 of pSK1 for use in EMSAs with increasing amounts of purified Rep protein $(0-8 \mu \mathrm{g})$ in the presence of $2 \mu \mathrm{g}$ non-specific poly $(\mathrm{dI}-\mathrm{dC})$ competitor DNA. The band shifts observed and specific competitor DNA titration reactions showed that the pSK1 Rep protein bound both quantitatively and specifically to the $250 \mathrm{bp}$ fragment (data not shown). The pSK1 Rep binding sites were further delineated by DNase I footprinting using the same $250 \mathrm{bp}$ fragment. The pSK1 Rep protein was found to protect a region corresponding to four repeat sequences that we have designated Rep box 1 to box 4 (Fig. 4). The Rep boxes are 


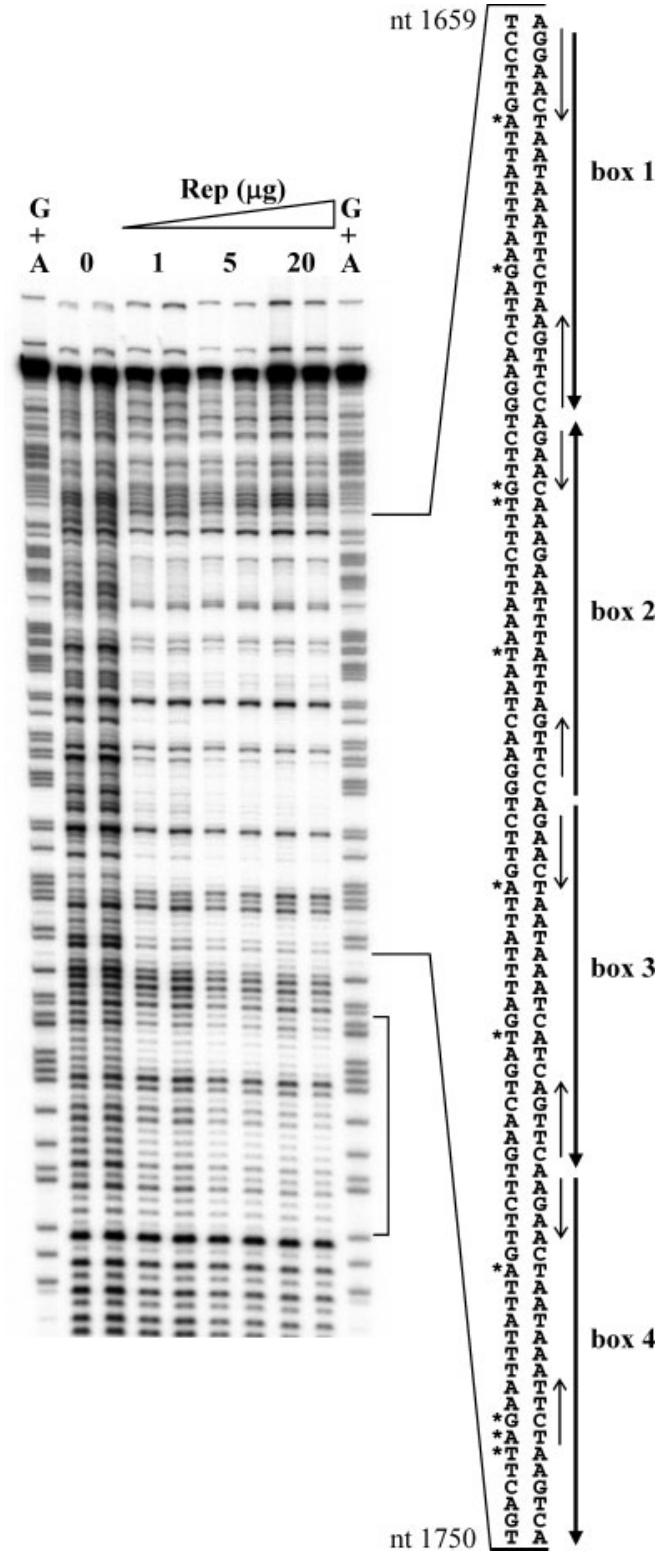

Fig. 4. Identification of Rep binding sites by DNase I footprinting. The pSK1 region from nucleotide 1593 to 1845 was PCR amplified, end-labelled and then incubated with $0,1,5$ or $20 \mu \mathrm{g}$ purified Rep protein. The nucleoprotein complexes were digested with DNase I before separation on a denaturing $8 \%$ polyacrylamide gel alongside a $\mathrm{G}+\mathrm{A}$ sequencing ladder. Four repeat sequences (Rep boxes 1-4), located between pSK1 coordinates 1659 and 1750, were protected from DNase I cleavage by Rep. Large arrows indicate the orientations of the Rep boxes and small arrows indicate short terminal inverted repeats within each of the Rep boxes. Asterisks indicate nucleotides that remained sensitive to DNase I even in the presence of excess Rep protein. A second region found immediately downstream of the Rep boxes was observed to be partially protected by Rep protein.

arranged in tandem with the exception of Rep box 2, which has an inverted orientation. Rep box 1 begins at nucleotide
1661 and Rep box 4 ends at nucleotide 1751 and the consensus is a 22-mer of the sequence $5^{\prime}$-RGA ACT AAT AAA TYM THW GTY M-3'. Immediately downstream of the four Rep boxes, an additional $20 \mathrm{bp}$ region (from nucleotide 1759 to 1778 ) appeared to be partially protected from DNase I cleavage by bound Rep molecules. It is unclear at this time whether this mild protection is due to direct Rep protein interaction or to topological changes induced by Rep in this region, such as strand opening, making it less sensitive to DNase I digestion.

\section{DISCUSSION}

The results described here have revealed that at a gross level, the basic features and organization of the pSK1 replication region resemble those of pSK41. In particular, copy number control is mediated by an antisense RNA molecule complementary to the leader region of the rep message, and the Rep protein binds to iterated sequences located centrally within the rep coding sequence. The latter appears to be a common feature of this type of replication system since equivalent repeats are evident even in distantly related replicons from other genera; Rep binding has also been demonstrated for the Bacillus subtilis and Enterococcus faecalis plasmids pLS32 (Tanaka et al., 2005) and pAD1 (Francia et al., 2004), respectively. The Rep boxes of pSK1 and pSK41 are similar in size (22-24 nucleotides) but the sequences of the repeats themselves bear little similarity between the two plasmids. Additionally, in contrast to the directly repeated organization seen in pSK41, the second Rep box of pSK1 is in an inverted orientation (Fig. 4). A number of nucleotides within the pSK1 footprint are not completely protected from DNase I cleavage in the presence of excess Rep (Fig. 4). This, and the spacing between the unprotected nucleotides, suggests that the Rep molecules make contact with one face of the double helix. Indeed the lengths of the Rep boxes are equal to approximately two helical turns of DNA. The terminal four to six nucleotides of each pSK1 Rep box are also inverted repeats (Fig. 4), and inspection of the pSK41 Rep boxes and those predicted for other replicons in the family (Fig. 5) reveals similar features. Such symmetry within each Rep box may be important for Rep interactions.

In this study, the pSK1 rep TSP was identified $78 \mathrm{bp}$ upstream of that reported previously (Simpson et al., 2003). Detection of a primer extension product for this TSP was facilitated by the use of minireplicons carrying $\mathrm{P}_{\text {rnaI }}$ mutations. We had previously noted this requirement when mapping the TSP for pSK41 rep (Kwong et al., 2004). It is likely that generation of the primer extension product is significantly reduced in the presence of RNAI because reverse transcriptase would need to displace duplexed RNAI in order to reach the $5^{\prime}$-end of rep mRNA. Since the previously inferred TSP was very close to the $5^{\prime}$-end of rnaI, the extension product detected by Simpson et al. (2003) might have resulted from reverse transcriptase stalling when it encountered duplexed RNAI. 


\begin{tabular}{|c|c|c|c|c|c|c|}
\hline Plasmid & $\mathbf{P}_{\text {rep }}$ & (6) & $\mathbf{P}_{\text {rnaI }}$ & RNAI & RBS & Rep box 1 \\
\hline SK1 & TTTATA-17bp-ТАATAT & 99 & TGCAC-17bp-TATAAT & 80 & ATGAGG & GGAACTAATAAATTCTAAGTTCCAG \\
\hline 9789 & ГТАТА-17bp-ТАATAT & & P-TATAAT & 80 & G & GGAACTTCCAAATTCACAGT \\
\hline SX267 & TTTATA-17bp-ТАATAT & & TGCAC-17bp-TATAAT & 81 & ATGAGG & GGAACTTCCAAATTCACAGTTCCAG \\
\hline PVRSA & TTTATA-17bp-ТАATAT & 96 & TTGCAC-17bp-TATAAT & 81 & ATGAGG & GGAACTTCCAAATTCACAGTTCCAG \\
\hline PNVH97A & TTTTAT-17bP-ТАTAAT & 188 & OP-TATAAT & 70 & AAGAGG & GGAGTCCCAAAATTTGGGACTCCAG \\
\hline SERP & TTTAT-17bp-TATAAT & 88 & TTGCAA-18bP-TATAAT & 70 & AAGAGG & GGAGTCCCAAAATTTGGGACTCCAG \\
\hline 80 & TTTTAT-17bp-TATAAT & 188 & OP-TATAAT & 71 & AAC & GGAGTCCCAAAATTTGGGACTCCAG \\
\hline $\mathrm{PNV}$ & TTTTAT-17bP-TATAAT & 205 & OP-TATAAT & 76 & AAGAGG & GGAATTTCGAAAATCAAAATTCCAG \\
\hline $\mathrm{pSE}-05$ & TTTAAT-17bp-TATAAT & 209 & OP-TATAAT & 80 & AAGAGG & GGAATTTCGAAAATCAAAATTCCAG \\
\hline 15 & TTTAT-17bp-TATAAT & 208 & TTGCAC-17bp-TATAAT & 77 & AAGAGG & GGACGTTCGATTTTCGAACGTCCAG \\
\hline pSR1 & ТTTTAT-17bp-ТАTАAT & 208 & TTGCAC-17bP-TATAAT & 77 & AAGAGG & GGAAGTTCGAAAATCGAACGTCCAG \\
\hline pssP2 & TTTAAC-17bp-ТАTTAT & 191 & TTGCAC-17bp-TATAAT & 78 & AAGAGG & GGACGTATCAAATTCATACGTCCAG \\
\hline 101 & TTTAAC-17 & 185 & TTG & 73 & & GTCCAG \\
\hline$P I-1$ & TTGTTA-17bP-ATTAAT & 246 & A-17bP-TATAAA & 91 & AA & GGAACTAAAA \\
\hline pSSP1 & TTGTTT-17bP-TATTAT & 215 & TTGCAC-17bP-TATAAT & 83 & AAGAGG & CAAACTTAAAAAATGGGACATTG \\
\hline SK41 & TTTTAA-17bp-TACTAT & 240 & TTGTAA-17bp-TATAAT & 83 & AAGGAG & GACAAGGAAGTGTCAAAAGGACAC \\
\hline
\end{tabular}

Fig. 5. Conserved elements in the replication control regions of staphylococcal multiresistance plasmids. Two of the plasmid designations have been abbreviated; pl9789 (pl9789::Tn552) and pSE-05 (pSE-12228-05). The replicons of plasmids pSK41, pUSA03 and pLW1043, as well as pVRSA and pSE-12228-04, respectively, are identical and only the former plasmids are included in each case. Experimentally determined and predicted promoter sequences for rep $\left(\mathrm{P}_{\text {rep }}\right)$ and rnal $\left(\mathrm{P}_{\text {rnal }}\right)$ and the lengths (nt) of the rep leaders and RNAI molecules are indicated. The predicted ribosome-binding sites (RBS) and the sequences of the first Rep box are also shown.

A 68 bp region upstream of $\mathrm{P}_{\text {rep }}$ was found to contain sequences essential for replication of pSK1, even when Rep was supplied in trans. A similar requirement has been noted for pSK41, where the upstream essential cis-acting DNA sequence is located within an $\mathrm{A}+\mathrm{T}$-rich region that contains a palindromic sequence (Kwong et al., 2004). The upstream cis-acting region of $\mathrm{pSK} 1$ does not have any significant sequence similarity with the analogous region of pSK41 but it also contains a region of dyad symmetry (nucleotides 1012 to 1036) that is A+T-rich. It is possible that these AT-rich palindromic sequences are recruited to the nucleoprotein complex formed by Rep at the ori $\mathrm{V}$, with the assistance of DNA-bending proteins, to form an active replication complex. Alternatively, these sequences might be important for $\mathrm{P}_{\text {rep }}$ activity, which could be required in cis, if for example transcripts from it act as primers for replication, in addition to serving as mRNA molecules for Rep expression. Further studies are needed to illuminate these possibilities.

Our findings are highly likely to be broadly relevant across the staphylococcal multiresistance plasmids because, based on Rep protein sequences, pSK41 and pSK1 represent divergent lineages in the multiresistance plasmid phylogeny (Firth et al., 2000), and additionally correspond to conjugative and non-conjugative prototypes. In this regard, detailed information about pSK1 is particularly important since the majority of known staphylococcal multiresistance plasmids are non-conjugative, and comparative analyses indicate that the conjugative plasmids, pSK41, pLW1043 and pUSA03 are very closely related to each other and are something of a special case (see below).
DNA sequence data for staphylococcal multiresistance plasmids has grown considerably in recent years; the databases currently contain replication region sequences for approximately 25 distinguishable replicons from a range of staphylococcal species. Alignment of selected representatives demonstrates conservation of a number of features identified in pSK1, as summarized in Fig. 5. Notably, in all cases the rep ribosome-binding site (RBS) is located within the distal arm of an inverted repeat. In pSK41 this inverted repeat is implicated in the repression of rep translation when RNAI binds to the rep mRNA leader (Kwong et al., 2006; see below). Located upstream of the inverted repeats are divergently oriented putative promoters that are expected to give rise to the antisense regulatory RNA molecules. These promoters have the consensus $5^{\prime}$-TTGCAM-3' (where $\mathrm{M}$ is A or C) separated by 17 or $18 \mathrm{bp}$ from the sequence $5^{\prime}$-TATAAT-3', corresponding to the -35 and -10 promoter sequences, respectively; their similarity to the canonical consensus suggests that that they are likely to be highly active, and this has been shown for pSK41 (Kwong et al., 2006). RNA folding predictions indicate that the antisense RNAs of the non-conjugative plasmids form two thermodynamically stable stem-loop secondary structures, as shown for pSK1 in Fig. 6. The $3^{\prime}$ stem-loops ( $\left.\mathrm{SL}_{\mathrm{RNAI}}-\mathrm{II}\right)$ typically have $11-$ 14 base pairings in the stems and 4-11 unpaired nucleotides in the loop regions that contain two consecutive cytosine residues. These stem-loop structures may also act as transcriptional terminators since most of them are followed immediately by poly(U) sequences typical of 


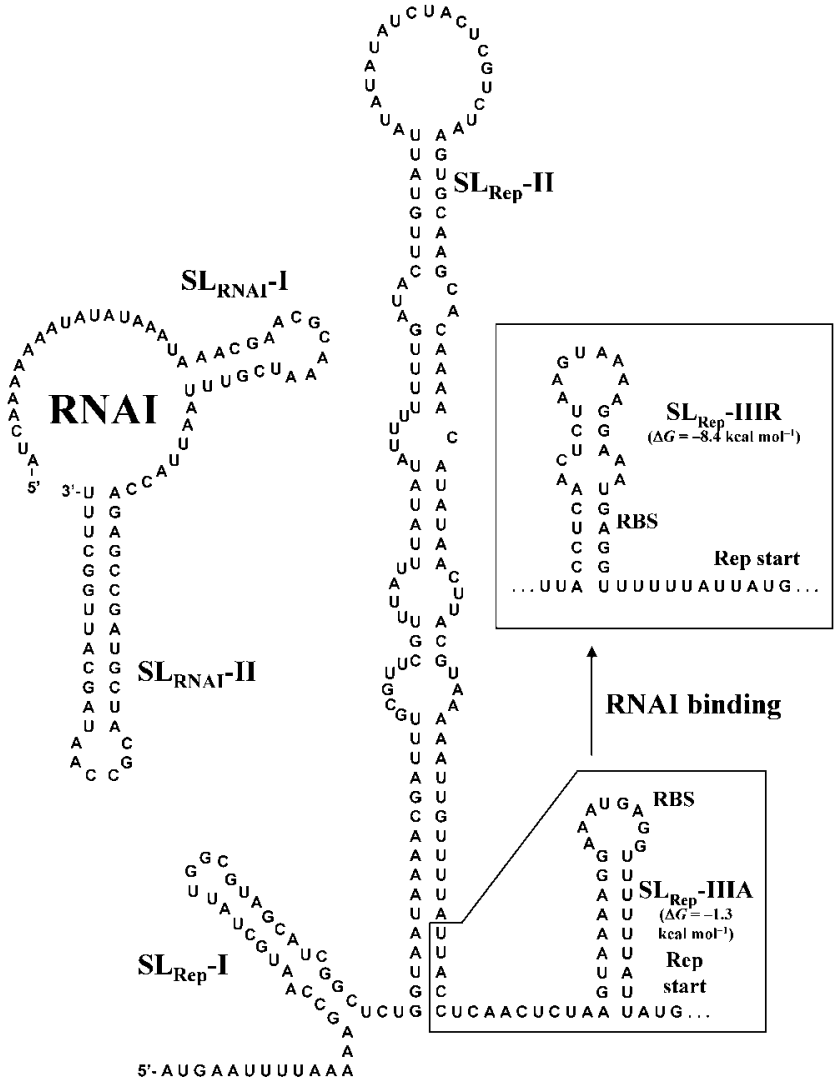

Rep mRNA leader

Fig. 6. Model for antisense RNA-mediated replication control of pSK1. The predicted secondary structures of RNAl and the Rep mRNA leader are shown with the Rep start codon and ribosomebinding site (RBS) boxed. In the absence of RNAl, the RBS is within a thermodynamically unstable stem-loop ( $S L_{\text {Rep }}-$ IIIA) and the rep mRNA is derepressed for translation. Upon RNAI binding the bases located at the base of $S L_{\text {Rep }}$-ll are predicted to pair with the rep RBS creating a new stem-loop structure $S L_{\text {Rep }}$-IIIR which is thermodynamically stable, and thus repressing Rep translation.

rho-independent terminators; RNAI lengths of 70 to $91 \mathrm{nt}$ are predicted. The $5^{\prime}$ stem-loops of the predicted antisense RNAs $\left(\mathrm{SL}_{\mathrm{RNAI}^{-}} \mathrm{I}\right)$ are more variable in sequence and structure and generally have higher free energy values than their 3' counterparts; however, their ubiquitous presence implies that they may be required for effective target mRNA inhibition.

Although generally less well conserved and having poorer matches to the consensus than those for rnaI, promoters directing rep gene transcription can now be recognized in the non-conjugative plasmids at positions equivalent to that of pSK1 $\mathrm{P}_{\text {rep }}$; in each case the rep leader region is predicted to fully encompass the corresponding rnaI gene. The rep mRNA leaders of the non-conjugative plasmids are predicted to possess considerable secondary structure, as exemplified by pSK1 (Fig. 6). As for pSK41, three stem-loops are predicted in the rep mRNA leader, although the largest $\left(\mathrm{SL}_{\mathrm{Rep}}-\mathrm{II}\right)$ differs markedly from the Y-shaped structure proposed for pSK41 and the other conjugative plasmids (Kwong et al., 2006). Nonetheless, RNAI binding to rep mRNA is similarly expected to induce an alteration of $\mathrm{SL}_{\mathrm{Rep}}$-IIIA (active) resulting in occlusion of the rep RBS within a stem ( $\mathrm{SL}_{\mathrm{Rep}}$-IIIR; repressed), such that rep translation initiation is likely to be inhibited. RNAImediated repression of rep translation has been demonstrated for pSK41 (Kwong et al., 2006), and thus it would appear, despite differing in sequence and RNA secondary structure, that the non-conjugative staphylococcal multiresistance plasmids utilize the same basic mechanism of copy number control.

Notwithstanding the similarities noted above, some important differences are evident between the replication regions of pSK41 and pSK1, and between the conjugative and non-conjugative plasmids generally. Notably, the mutation in the pSK1 RNAI promoter described here resulted in only an approximately eightfold increase in plasmid copy number, whereas the equivalent mutation in a pSK41-based replicon resulted in an approximately 35fold increase in copy number (Kwong et al., 2006), despite both plasmids having similar copy numbers of 5-8 under repressed conditions (Grkovic et al., 2003; Kwong et al., 2006). Such a disparity might be a consequence of differences in the RNA structures noted above, promoter strengths and/or the efficiency of rep translation. Although the generality of this difference is unknown, this observation does imply significant differentiation between the copy number control systems of pSK1 and pSK41, which may be relevant to the compatibility of the two plasmids, particularly given the potent RNAI-mediated incompatibility against self described here for pSK1.

In most of the non-conjugative plasmids, the rep gene shares an upstream intergenic region with a divergently transcribed gene homologous to pSK1 par. This gene on pSK1 has been shown to enhance plasmid segregation stability, and it has been suggested that it might constitute a novel partitioning system (Simpson et al., 2003). In this regard, it is notable that in the two exceptions that lack such a homologue, pPI-1 and pSSP1, a pair of genes resembling a type $\mathrm{Ib}$ active partitioning system are evident, in the equivalent position immediately upstream of their respective rep genes (Aso et al., 2005). These plasmids, from coagulase-negative species, clearly constitute a distinct lineage since they both encode an unusually long replication initiation protein as a consequence of a partial rep gene duplication (Aso et al., 2005). The conjugative plasmids provide a third distinct variation on this theme, since they possess a type II partitioning system (MøllerJensen et al., 2002; Schumacher et al., 2007), but in this case a single small ORF of unknown function separates the two-gene par operon from the rep gene. Thus, the diversification of plasmid maintenance systems appears to have been an important element in the divergence of 
multiresistance plasmid lineages, and to have affected the copy number control systems used by these plasmids.

\section{ACKNOWLEDGEMENTS}

This work was supported by the National Health and Medical Research Council of Australia, Project Grant 307620.

\section{REFERENCES}

Allignet, J. \& El Solh, N. (1999). Comparative analysis of staphylococcal plasmids carrying three streptogramin-resistance genes: vat-vgb-vga. Plasmid 42, 134-138.

Anthonisen, I. L., Sunde, M., Steinum, T. M., Sidhu, M. S. \& Sørum, H. (2002). Organization of the antiseptic resistance gene qacA and Tn552-related $\beta$-lactamase genes in multidrug-resistant Staphylococcus haemolyticus strains of animal and human origins. Antimicrob Agents Chemother 46, 3606-3612.

Apisiridej, S., Leelaporn, A., Scaramuzzi, C. D., Skurray, R. A. \& Firth, N. (1997). Molecular analysis of a mobilizable theta-mode trimethoprim resistance plasmid from coagulase-negative staphylococci. Plasmid 38, 13-24.

Aso, Y., Koga, H., Sashihara, T., Nagao, J., Kanemasa, Y., Nakayama, J. \& Sonomoto, K. (2005). Description of complete DNA sequence of two plasmids from the nukacin ISK-1 producer, Staphylococcus warneri ISK1. Plasmid 53, 164-178.

Ausubel, F. M., Brent, R., Kingston, R. E., Moore, D. D., Smith, J. A., Seidman, J. G. \& Struhl, K. (1987). Current Protocols in Molecular Biology. New York: Wiley.

Birnboim, H. C. \& Doly, J. (1979). A rapid alkaline extraction procedure for screening recombinant plasmid DNA. Nucleic Acids Res 7, 1513-1523.

Diep, B. A., Gill, S. R., Chang, R. F., Phan, T. H., Chen, J. H., Davidson, M. G., Lin, F., Lin, J., Carleton, H. A. \& other authors (2006). Complete genome sequence of USA300, an epidemic clone of communityacquired meticillin-resistant Staphylococcus aureus. Lancet 367, 731-739.

Firth, N. \& Skurray, R. A. (2006). Genetics: accessory elements and genetic exchange. In Gram-Positive Pathogens, 2nd edn, pp. 413-426. Edited by V. A. Fischetti, R. P. Novick, J. J. Ferretti, D. A. Portnoy \& J. I. Rood. Washington, DC: American Society for Microbiology.

Firth, N., Apisiridej, S., Berg, T., O'Rourke, B. A., Curnock, S., Dyke, K. G. H. \& Skurray, R. A. (2000). Replication of staphylococcal multiresistance plasmids. J Bacteriol 182, 2170-2178.

Francia, M. V., Fujimoto, S., Tille, P., Weaver, K. E. \& Clewell, D. B. (2004). Replication of Enterococcus faecalis pheromone-responding plasmid pAD1: location of the minimal replicon and oriV site and RepA involvement in initiation of replication. J Bacteriol 186, 5003-5016.

Gering, M., Götz, F. \& Bruckner, R. (1996). Sequence and analysis of the replication region of the Staphylococcus xylosus plasmid pSX267. Gene 182, 117-122.

Gill, S. R., Fouts, D. E., Archer, G. L., Mongodin, E. F., Deboy, R. T., Ravel, J., Paulsen, I. T., Kolonay, J. F., Brinkac, L. \& other authors (2005). Insights on evolution of virulence and resistance from the complete genome analysis of an early methicillin-resistant Staphylococcus aureus strain and a biofilm-producing methicillinresistant Staphylococcus epidermidis strain. J Bacteriol 187, 2426-2438.

Grkovic, S., Brown, M. H., Hardie, K. M., Firth, N. \& Skurray, R. A. (2003). Stable low-copy number Staphylococcus aureus shuttle vectors. Microbiology 149, 785-794.
Kreiswirth, B. H., Lofdahl, S., Betley, M. J., O’Reilly, M., Schleivert, P. M., Bergdoll, M. S. \& Novick, R. P. (1983). The toxic shock syndrome exotoxin is not detectably transmitted by a prophage. Nature 305, 709-712.

Kuroda, M., Ohta, T., Uchiyama, I., Baba, T., Yuzawa, H., Kobayashi, I., Cui, L., Oguchi, A., Aoki, K. \& other authors (2001). Whole genome sequencing of methicillin-resistant Staphylococcus aureus. Lancet 357, 1225-1240.

Kuroda, M., Yamashita, A., Hirakawa, H., Kumano, M., Morikawa, K., Higashide, M., Maruyama, A., Inose, Y., Matoba, K. \& other authors (2005). Whole genome sequence of Staphylococcus saprophyticus reveals the pathogenesis of uncomplicated urinary tract infection. Proc Natl Acad Sci U S A 102, 13272-13277.

Kwong, S. M., Skurray, R. A. \& Firth, N. (2004). Staphylococcus aureus multiresistance plasmid pSK41: analysis of the replication region, initiator protein binding and antisense RNA regulation. Mol Microbiol 51, 497-509.

Kwong, S. M., Skurray, R. A. \& Firth, N. (2006). Replication control of staphylococcal multiresistance plasmid pSK41: an antisense RNA mediates dual-level regulation of Rep expression. J Bacteriol 188, 4404-4412.

Martin, K. A., Friedman, S. A. \& Austin, S. J. (1987). Partition site of the P1 plasmid. Proc Natl Acad Sci U S A 84, 8544-8547.

Møller-Jensen, J., Jensen, R. B., Löwe, J. \& Gerdes, K. (2002). Prokaryotic DNA segregation by an actin-like filament. EMBO J 21, 3119-3127.

O’Brien, F. G., Price, C., Grubb, W. B. \& Gustafson, J. E. (2002). Genetic characterisation of the fusidic acid and cadmium resistance determinants of Staphylococcus aureus plasmid pUB101. J Antimicrob Chemother 50, 313-321.

Paulsen, I. T., Firth, N. \& Skurray, R. A. (1997). Resistance to antimicrobial agents other than $\beta$-lactams. In The Staphylococci in Human Disease, pp. 175-212. Edited by K. B. Crossley \& G. L. Archer. New York: Churchill Livingstone.

Sambrook, J., Fritsch, E. F. \& Maniatis, T. (1989). Molecular Cloning: a Laboratory Manual, 2nd edn. Cold Spring Harbor, NY: Cold Spring Harbor Laboratory.

Schenk, S. \& Laddaga, R. A. (1992). Improved method for electroporation of Staphylococcus aureus. FEMS Microbiol Lett 73, 133-138.

Schumacher, M. A., Glover, T. C., Brzoska, A. J., Jensen, S. O., Dunham, T. D., Skurray, R. A. \& Firth, N. (2007). Segrosome structure revealed by a complex of ParR with centromere DNA. Nature 450, 1268-1271.

Shaw, W. V. (1975). Chloramphenicol acetyltransferase from chloramphenicol-resistant bacteria. Methods Enzymol 43, 737-755.

Simpson, A. E., Skurray, R. A. \& Firth, N. (2003). A single gene on the staphylococcal multiresistance plasmid pSK1 encodes a novel partitioning system. J Bacteriol 185, 2143-2152.

Stark, M. J. (1987). Multicopy expression vectors carrying the lac repressor gene for regulated high-level expression of genes in Escherichia coli. Gene 51, 255-267.

Tanaka, T., Ishida, H. \& Maehara, T. (2005). Characterization of the replication region of plasmid pLS32 from the Natto strain of Bacillus subtilis. J Bacteriol 187, 4315-4326.

Thompson, J. D., Higgins, D. G. \& Gibson, T. J. (1994). CLUSTAL W: improving the sensitivity of progressive multiple sequence alignment through sequence weighting, position-specific gap penalties and weight matrix choice. Nucleic Acids Res 22, 4673-4680.

Weigel, L. M., Clewell, D. B., Gill, S. R., Clark, N. C., McDougal, L. K., Flannagan, S. E., Kolonay, J. F., Shetty, J., Killgore, G. E. \& Tenover, F. C. (2003). Genetic analysis of a high-level vancomycin-resistant isolate of Staphylococcus aureus. Science 302, 1569-1571. 
Zhang, Y. Q., Ren, S. X., Li, H. L., Wang, Y. X., Fu, G., Yang, J., Qin, Z. Q., Miao, Y. G., Wang, W. Y. \& other authors (2003). Genome-based analysis of virulence genes in a non-biofilm-forming Staphylococcus epidermidis strain (ATCC 12228). Mol Microbiol 49, 1577-1593.
Zuker, M. (2003). Mfold web server for nucleic acid folding and hybridisation prediction. Nucleic Acids Res 31, 3406-3415.

Edited by: T. Msadek 